\title{
Triatoma pintodiasi sp. nov. do subcomplexo T. rubrovaria (Hemiptera, Reduviidae, Triatominae)
}

Triatoma pintodiasi sp. nov. of the T. rubrovaria subcomplex (Hemiptera, Reduviidae, Triatominae)

Triatoma pintodiasi sp. nov. del subcomplejo T. rubrovaria (Hemiptera, Reduviidae, Triatominae)

José Jurberg

Laboratório Nacional e Internacional de Referência em Taxonomia de Triatomíneos, Instituto Oswaldo Cruz/Fiocruz, Rio de Janeiro, Rio de Janeiro, Brasil

\section{Vanda Cunha}

Laboratório Nacional e Internacional de Referência em Taxonomia de Triatomíneos, Instituto Oswaldo Cruz/Fiocruz, Rio de Janeiro, Rio de Janeiro, Brasil

\section{Solange Cailleaux}

Laboratório Nacional e Internacional de Referência em Taxonomia de Triatomíneos, Instituto Oswaldo Cruz/Fiocruz, Rio de Janeiro, Rio de Janeiro, Brasil

\section{Raquel Raigorodschi}

Laboratório Nacional e Internacional de Referência em Taxonomia de Triatomíneos, Instituto Oswaldo Cruz/Fiocruz, Rio de Janeiro, Rio de Janeiro, Brasil
Michele Souza Lima

Laboratório de Bioquímica de Lipídeos e Lipoproteínas, Instituto de Bioquímica Médica, Universidade Federal do Rio de Janeiro, Rio de Janeiro, Rio de Janeiro, Brasil

Dayse da Silva Rocha

Laboratório Nacional e Internacional de Referência em Taxonomia de Triatomíneos, Instituto Oswaldo Cruz/Fiocruz, Rio de Janeiro, Rio de Janeiro, Brasil

Felipe Ferraz Figueiredo Moreira

Laboratório Nacional e Internacional de Referência em Taxonomia de Triatomíneos, Instituto Oswaldo Cruz/Fiocruz, Rio de Janeiro, Rio de Janeiro, Brasil

\section{RESUMO}

Uma nova espécie críptica de Triatoma é descrita dentro do subcomplexo T. rubrovaria. As diferenças entre T. pintodiasi sp. nov. e T. circummaculata incluem, entre outras, o padrão cromático e diferenças morfológicas nas estruturas fálicas, como nos parâmeros, suporte do falosoma, processo do endosoma e vesica. Análises bioquímicas realizadas na hemolinfa e a comparação morfométrica da cabeça também registraram diferenças entre as duas espécies e outras do subcomplexo T. rubrovaria.

Palavras-chave: Doença de Chagas; Taxonomia; Triatominae.

\section{INTRODUÇÃO}

Em 2006 foi concretizada uma expedição ao Estado do Rio Grande do Sul, com a finalidade de capturar triatomíneos para enriquecer o acervo do insetário do Laboratório Nacional e Internacional de Referência em Taxonomia de Triatomíneos (LNIRTT), do Instituto Oswaldo

Correspondência / Correspondence / Correspondencia:

José Jurberg

Instituto Oswaldo Cruz/FIOCRUZ

Laboratório Nacional e Internacional de Referência em Taxonomia de Triatomíneos

Av. Brasil, $n^{\circ}$ 4365. Bairro: Manguinhos

CEP: 21045-900 Rio de Janeiro-Rio de Janeiro-Brasil

Tel.: + 55 (21) 2562-7317 / (21) 2562-1623

E-mail: jiurberg@ioc.fiocruz.br
Cruz, da Fundação Oswaldo Cruz (Fiocruz). A equipe do laboratório coletou 14 exemplares (ninfas e adultos) ao desfazer parte de uma cerca de pedras na localidade do Rincão, Nossa Senhora das Graças, no Município de

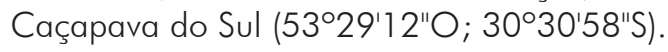

Durante a análise do material, notou-se uma semelhança entre o colorido marcante dos adultos capturados (Figura 1) e o observado em Triatoma carcavalloi Jurberg, Rocha e Lent, 1998 (Figura 2C), porém os insetos apresentavam tamanho mais reduzido, 1,2,3,4 (Figuras 1 e 2B). Uma análise acurada seguindo os padrões das chaves elaboradas por Lent e Wygodzinsky ${ }^{5} \mathrm{e}$ Carcavallo et al $\left(1998^{6}, 1999^{7}\right)$ nortearam a diagnose do lote a Triatoma circummaculata (Stål, 1859); no entanto, os adultos apresentavam variações em relação ao padrão cromático e morfológico. 


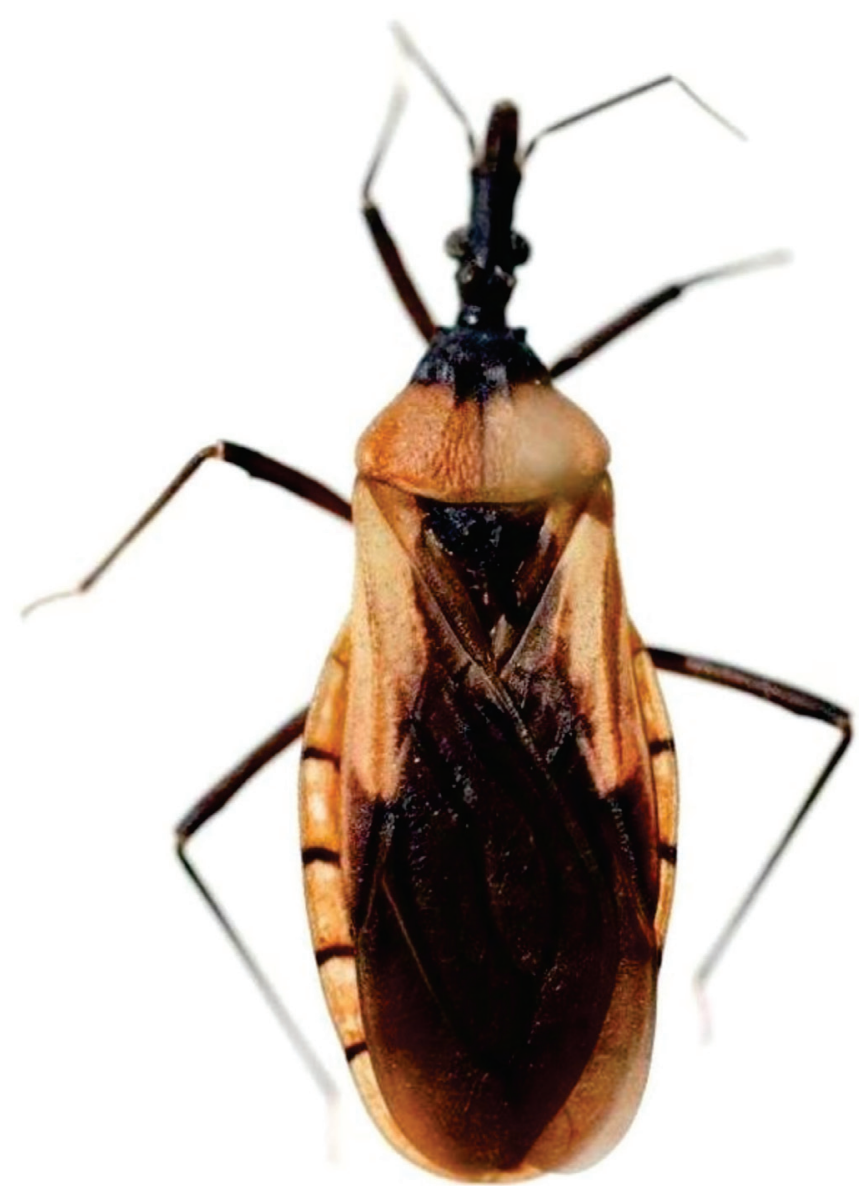

Figura 1 - Triatoma pintodiasi sp. nov. macho vista dorsal

A

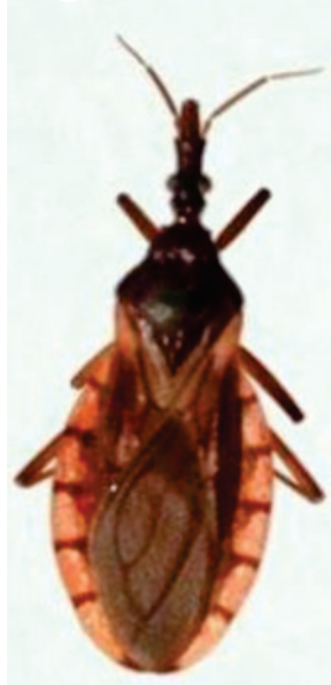

B

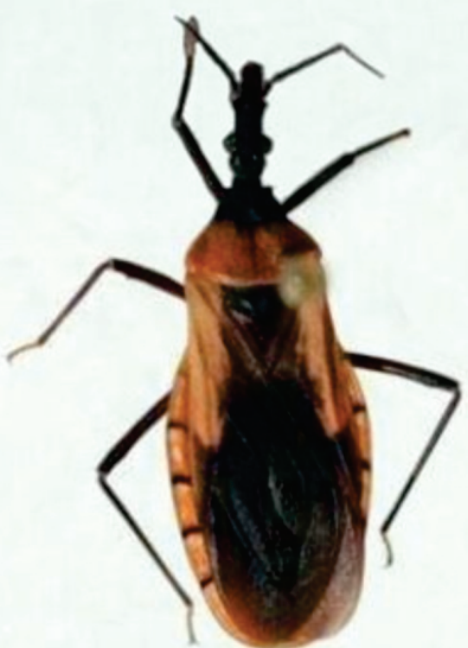

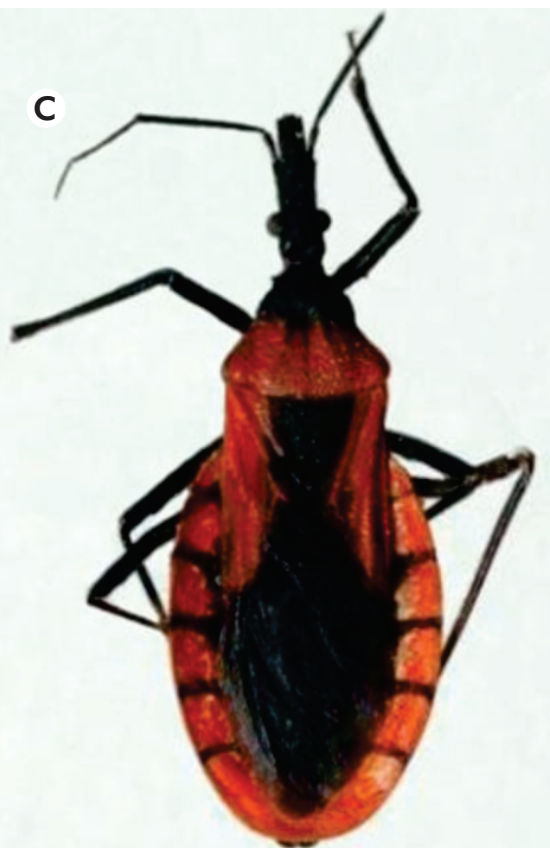

A - Triatoma circummaculata (Stål, 1859); B - Triatoma pintodiasi sp. nov.; C - Triatoma carcavalloi Jurberg, Rocha e Lent, 1998 [todos sob mesmo aumento].

Figura 2 - Visão comparativa entre espécies de Triatoma

Estas divergências levaram ao aprofundamento das análises comparativas das variedades cromáticas e morfológicas existentes no universo que é definido como $T$. circummaculata e T. carcavalloi, com exame dos exemplares existentes nas coleções Herman Lent e Rodolfo Carcavallo, do Instituto Oswaldo Cruz, bem como do material recém- chegado do campo e mantido no insetário do LNIRTT e fotos de espécimes do Museu de Berlim (Figura 3), onde se acha depositado o holótipo de T. circummaculata. Após essas análises, chegou-se à conclusão que o material oriundo de Caçapava do Sul representava uma nova espécie, críptica em relação à $T$. circummaculata. 


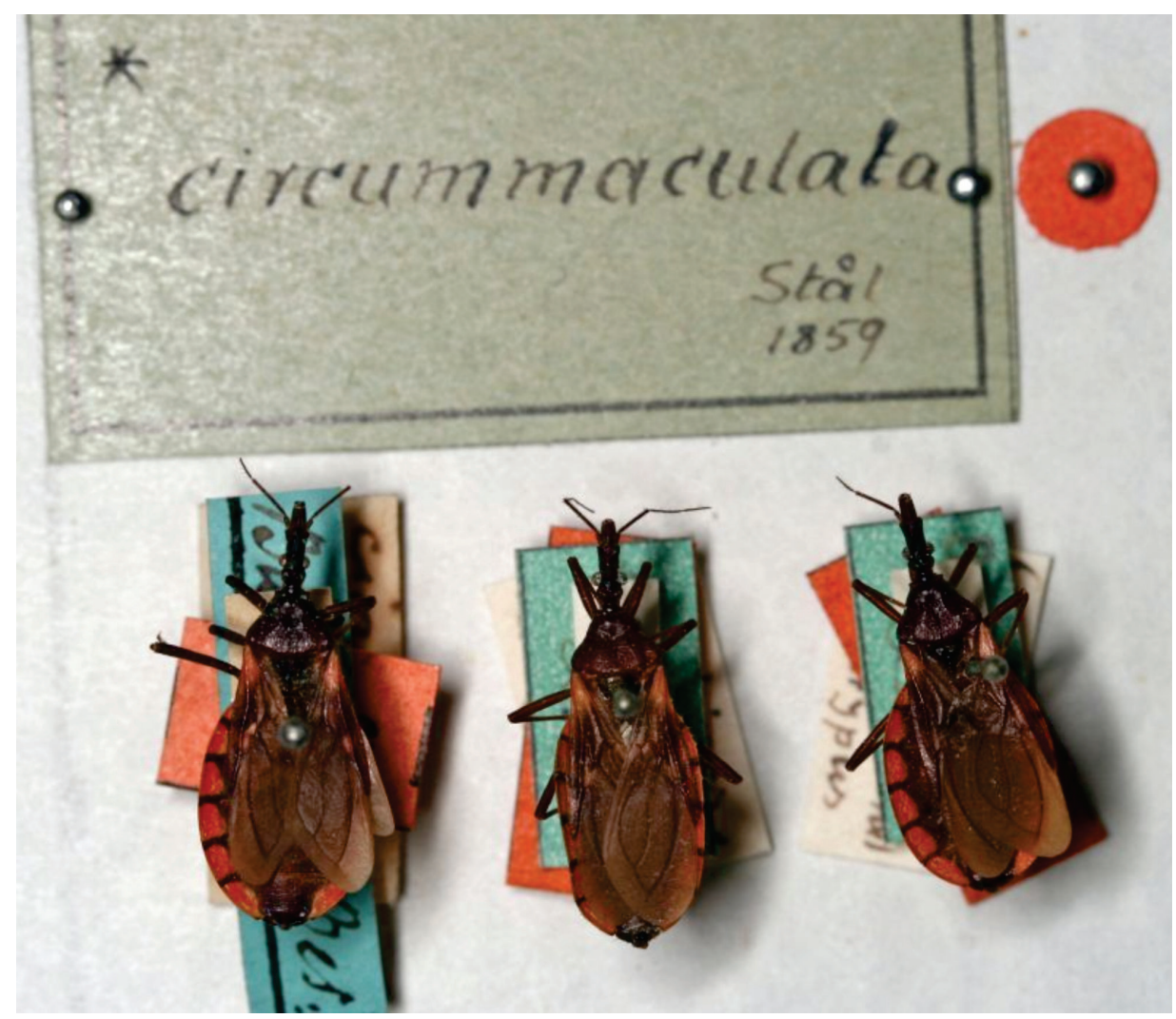

Figura 3 - Triatoma circummaculata (Stål, 1859); tipos depositados no Museum de Berlim

Cabe ressaltar que T. circummaculata pode apresentar variabilidade cromática, com o lobo posterior do pronoto totalmente negro (Figuras $2 \mathrm{~A}$ e 3 ) ou totalmente vermelho, de modo similar a T. rubrovaria (Blanchard, 1843). Ambas são encontradas naturalmente infectadas pelo Trypanosoma $\mathrm{cruzi}^{8}$, vivem abrigadas entre as frinchas de pedregais e raramente são coletadas em habitações humanas ${ }^{9}$. Nessas condições, pressupõe-se estarem mais protegidas das intempéries e terem um ciclo biológico mais equilibrado, não só em relação ao micro-habitat, mas também às fontes alimentares, pois ali vivem anfíbios, répteis e artrópodes. No laboratório, os representantes da espécie nova são mantidos há seis anos se alimentando de camundongos Mus musculus (Linnaeus, 1758), e sua progênie apresenta $\circ$ mesmo padrão morfocromático sem variações nas inúmeras gerações.

Com o objetivo de ampliar o conhecimento acerca das espécies que compõem o gênero Triatoma Laporte, 1832, descreve-se a espécie nova e compara-se com outras espécies do subcomplexo T. rubrovaria por meio de análises morfocromáticas, morfométricas e bioquímicas.

\section{MATERIAIS E MÉTODOS}

Todo o material citado nos resultados encontra-se depositado na Coleção Herman Lent - Instituto Oswaldo Cruz/Fiocruz. As estruturas fálicas foram analisadas após a dissecção do $8^{\circ}$ e $9^{\circ}$ segmentos do corpo do inseto, seguida pelo tratamento com hidróxido de potássio a $10 \%$ por tempo variável, até que toda matéria mole tivesse sido destruída, e passagem por fenol e creosoto de faia. Posteriormente, o material foi desenhado em câmara clara, assim como as estruturas não genitais dos exemplares. O material dissecado foi preservado em bálsamo do Canadá entre lâmina e lamínula e incorporado à Coleção Herman Lent com o mesmo número do inseto. A terminologia das estruturas fálicas segue aquela usada por Jurberg et $\mathrm{al}^{2}$. As descrições e figuras do falo foram feitas com o mesmo distendido.

Para a morfometria geométrica foram utilizados dez espécimes adultos de Triatoma pintodiasi sp. nov., T. rubrovaria e T. carcavalloi, e cinco de T. circummaculata, incluindo machos e fêmeas. Todos foram fixados em lâmina na posição dorso-ventral e, com o auxílio de uma câmera digital Nikon Coolpix 990, tiveram suas regiões cefálicas fotografadas. Posteriormente, as imagens foram digitalizadas e marcaram-se sete pontos cartesianos (landmarks) com o programa TPSDig, versão $2.10^{10}$ (Figura 4). Por meio do programa TPSrelw, versão $1.45^{11}$, os pontos cartesianos foram submetidos à análise generalizada de procrustes (AGP), gerando uma matriz. Esta foi convertida em valores numéricos, seguindo-se a redução do número de variáveis e análise multivariada, que origina os componentes principais (CPs).

Os componentes gerados a partir da análise dos componentes principais (ACP) foram utilizados na análise discriminante (AD) que, por sua vez, gerou fatores discriminantes (Canons). A partir do Canon um e Canon dois foi montado um mapa fatorial para visualizar a posição de cada espécie. Essas análises foram realizadas por meio do programa JMP, versão 3.2.6 (SAS) ${ }^{12}$. Para obtenção das placas delgadas (thin-plate splines), foi utilizado o programa TPSregr, versão $1.15^{11}$, permitindo uma visualização das diferenças entre a menor e a maior espécie. 


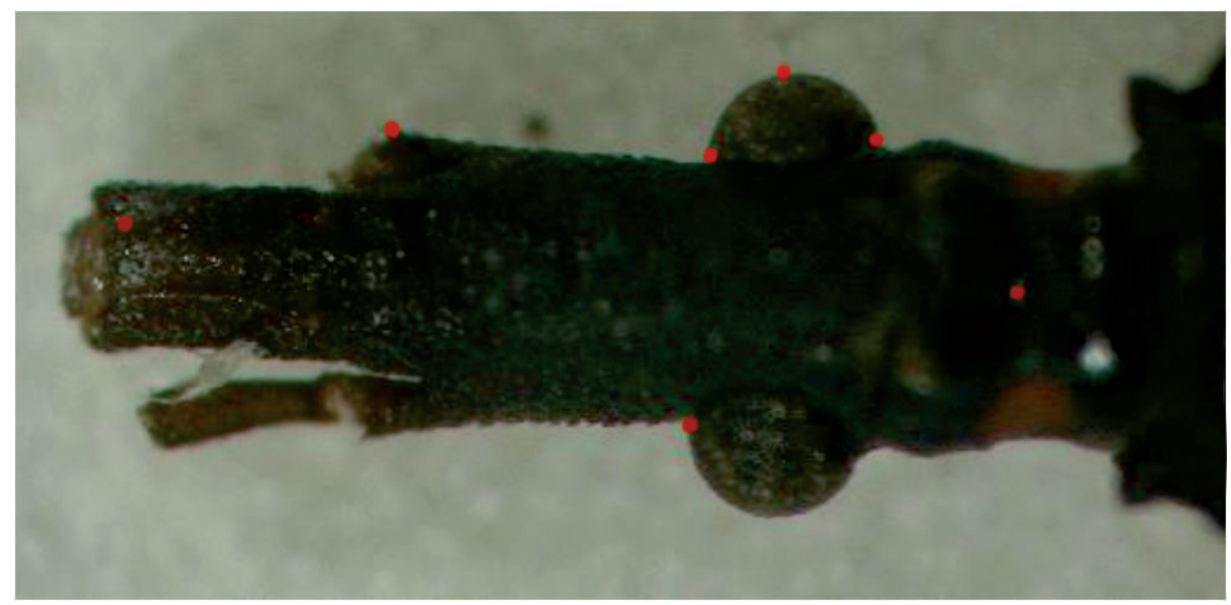

Os sete pontos em vermelho correspondem aos pontos cartesianos marcados pelo software TPSdig.

Figura 4 - Região cefálica de adulto de Triatoma pintodiasi sp. nov.

Os espécimes de T. circummaculata e T. pintodiasi sp. nov. foram mantidos a $28^{\circ} \mathrm{C}$, com umidade de 60 $70 \%$, na colônia de insetos do LNIRTT. A hemolinfa foi coletada das extremidades das pernas no sétimo dia após a alimentação seguida de leve pressão sobre o abdome, de acordo com Van Sande e Karcher ${ }^{13}$. A hemolinfa foi reunida em tubos na presença de cristais de feniltiouréia, EDTA $5 \mathrm{mM}$ e uma mistura de inibidores de proteases, preparados em $\mathrm{NaCl} 0,15 \mathrm{M}$ : SBTI (soybean trypsin inhibitor) 0,05 mg/mL, Leupeptina 0,05 mg/mL, LBTI (lima bean trypsin inhibitor) $0,05 \mathrm{mg} / \mathrm{mL}$, benzamidina $1 \mathrm{mM}$ e antipaína $0,05 \mathrm{mg} / \mathrm{mL}$, sendo estas as concentrações finais após a diluição com hemolinfa.

As concentrações de proteína foram determinadas pelo método de Lowry ${ }^{14}$, usando-se soro-albumina bovina como padrão. Para o procedimento da dosagem, foram misturadas as soluções de trabalho. Na solução alcalina tartarato de sódio e potássio, foram adicionados solução alcalina (20 g de $\mathrm{Na}_{3} \mathrm{CO}_{3}, 100 \mathrm{~mL}$ de $\mathrm{NaOH} 1 \mathrm{~N}$ e água), tartarato de sódio e potássio e sulfato de cobre. Na solução de Folin foram adicionados folin e água. Em uma placa de poliestireno de 96 poços foram adicionados $100 \mu \mathrm{L}$ de solução alcalina tartarato de sódio e potássio, $22 \mu \mathrm{L}$ de água e $11 \mu \mathrm{L}$ de folin. Para a realização da curva padrão, nesses poços foi adicionado de $1 \mu \mathrm{l}$ até $7 \mu \mathrm{l}$ de BSA. Nos outros poços foi adicionado $1 \mu \mathrm{g}$ da amostra. Após 20 min, a leitura da dosagem de proteínas foi realizada em um leitor de Elisa no comprimento de ondas de $660 \mathrm{~nm}$.

Posteriormente, as amostras de hemolinfa de T. circummaculata e T. pintodiasi sp. nov. foram submetidas à eletroforese em gel de poliacrilamida a $10 \%$. $\bigcirc$ gel de eletroforese em condições desnaturantes (SDS-PAGE) foi preparado de acordo com o método de Laemmli' ${ }^{15}$. Ao término da corrida, o gel foi corado com Coomasie Brilliant Blue R 0,3\% p/v em solução de metanol a $46 \%$ e ácido acético a $9 \%$ e descorado em solução com metanol $46 \%$, ácido acético $9 \%$ e $45 \%$ de água. O padrão de alta massa molecular utilizado inclui as seguintes proteínas: miosina (250 KDa), fosforilase (148 KDa), BSA (98 KDa), dehidrogenase glutâmico (64 KDa), álcool dehidrogenase (50 KDa), anidrase carbônica (36 KDa), aprotinina (6 $\mathrm{KDa})$ e insulina (4 KDa).
Para as análises estatísticas dos resultados originados segundo os métodos acima, os valores dos testes de significância foram obtidos por meio do programa Graph Pad Prism 4.0, em que os valores de $P<0,05$ foram considerados significativos entre os grupos ao utilizar o Two Way Anova (teste de Turkey). As diferenças entre as amostras foram comparadas e estatisticamente avaliadas pelos valores de $\mathrm{P}$ com base em três ensaios distintos.

\section{RESULTADOS}

TRIATOMA PINTODIASI SP. NOV. JURBERG, CUNHA E ROCHA (FIGURAS 1 E 2B)

Etimologia: $O$ nome desta espécie é dedicado ao $\mathrm{dr}$. João Carlos Pinto Dias, historiador, eminente médico e famoso por suas pesquisas voltadas à doença de Chagas, tendo publicado dezenas de artigos científicos. Foi responsável, quando presidente da Fundação Nacional de Saúde, pela escolha e implantação de um centro de referência para vetores da doença de Chagas, o que resultou na criação do LNIRTT, em 1989.

Diagnose: Comprimento do macho $15 \mathrm{~mm}$; fêmea, $16 \mathrm{~mm}$. Coloração geral castanho-escura; antenas alternando cor escura no $1^{\circ}$ e $2^{\circ}$ segmentos e mais clara no $3^{\circ}$ e $4^{\circ}$. Pronoto com lobo anterior negro e lobo posterior alaranjado. Abdome mostrando conexivo alaranjado com as suturas intersegmentais envolvidas por uma faixa negra estreita, praticamente ausente entre o segundo e terceiro segmentos (Figura 5A).

Descrição: Cabeça mais longa que larga ao nível dos olhos; comprimento 3,12 mm; largura ao nível dos olhos 2,75 mm, proporção 1:0,8; cabeça mais longa que $\circ$ pronoto 1:0,79, região ante-ocular mais longa que a pós-ocular 1:0,39, pós-ocular com as bordas laterais levemente globosas, separada do pescoço por uma suave constrição. Genas de ápice arredondado, de superfície mais granulosa, ultrapassando o pós-clípeo, com inúmeros tubérculos setíferos decumbentes; jugas de ápice afilado chegando ao limite da base do pós-clípeo; lateralmente estão implantados os tubérculos anteníferos $(1+1)$ que não ultrapassam o ápice das jugas (Figuras $6 \mathrm{~A}$ e 6B). 
A

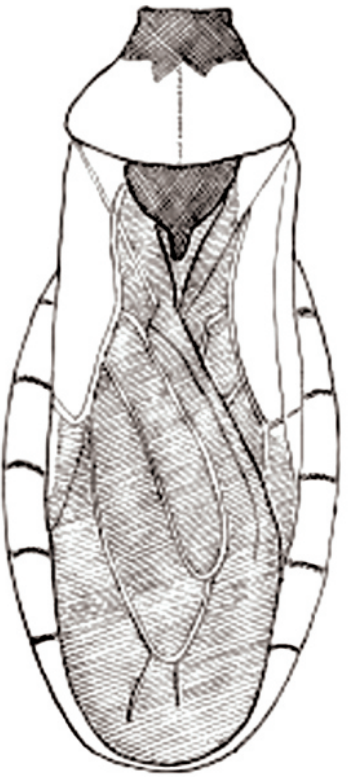

B

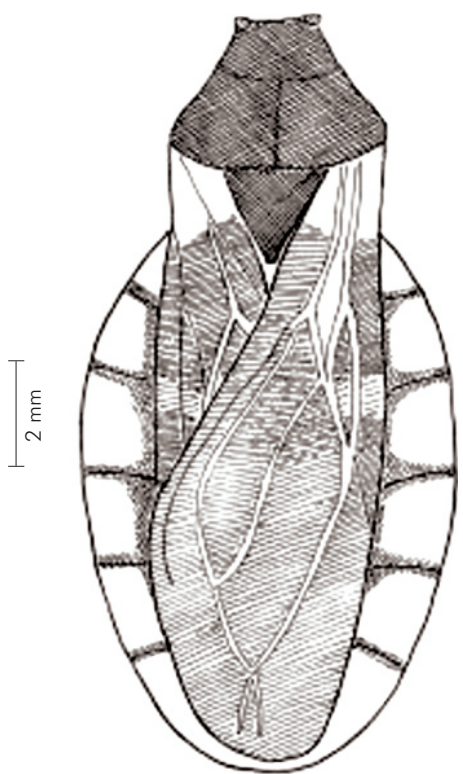

A - Triatoma pintodiasi sp. nov.; B - Triatoma circummaculata (Stål, 1859).

Figura 5 - Visão comparativa do tórax e abdome de Triatoma
A

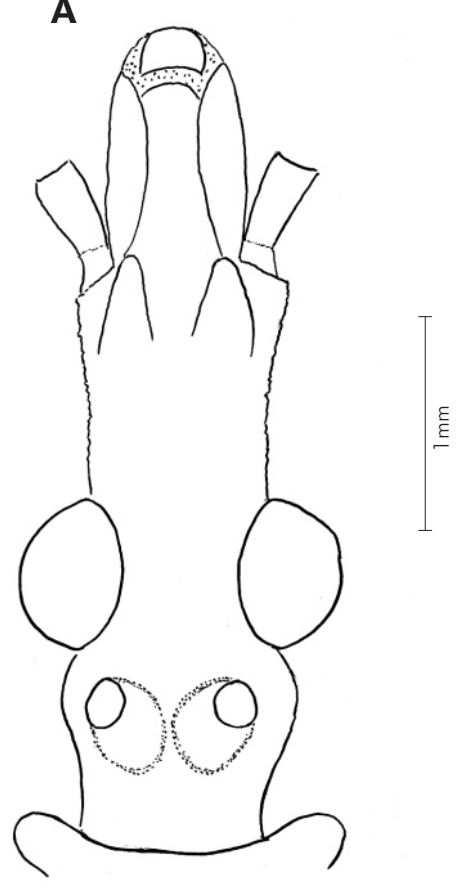

B

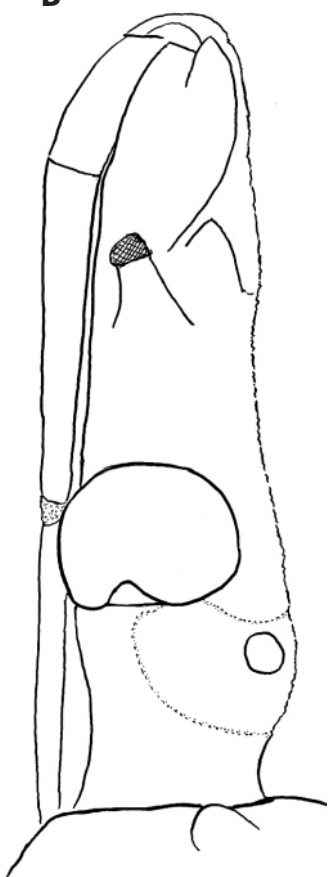

A - Cabeça em vista dorsal; B - Cabeça vista de perfil.

Figura 6 - Triatoma pintodiasi sp. nov.

Olhos situados na porção posterior da cabeça, bordos anterior e posterior paralelos, superior e inferior arredondados, o último ultrapassando o limite inferior da cabeça. Relação da largura do olho e a região interocular 1:1,66 (Synthlipsis) (Figuras 6A e 6B). Ocelos implantados em protuberâncias divergentes obliquamente para frente da cabeça (Figuras 6A e 6B).

Antenas implantadas em tubérculos anteníferos lateralmente situados, com $\circ 1^{\circ}$ segmento muito curto, não ultrapassando a região mediana das genas; $1^{\circ} \mathrm{e}$ $2^{\circ}$ segmentos de cor negra, $3^{\circ}$ e $4^{\circ}$ de cor clara, com numerosos pelos negros no $1^{\circ}$ e $2^{\circ}$ e iridescentes no $3^{\circ}$ e $4^{\circ}$, que apresentam numerosas tricobótrias. Proporção entre os artículos da antena 1:4,13:2,66:2,33.

Rostro de cor castanho-clara, achatado, $1^{\circ}$ segmento atingindo a região mediana das genas, $2^{\circ}$ segmento longo, atingindo a região mediana dos olhos e $3^{\circ}$ segmento menor que $\circ 2^{\circ}$, com o ápice tocando o bordo anterior do sulco estridulatório; proporções dos artículos do rostro 1:2,5:2,25 (Figura 6B).

Pronoto trapezoidal, lobo anterior totalmente negro, lobo posterior totalmente alaranjado/amarelado, com $1+1$ carenas submedianas que ultrapassam os limites do lobo; no anterior, as carenas são negras e, no posterior, amareladas. Linha mediana do pronoto com um sulco fracamente definido de cor negra. Ângulo ântero-lateral levemente projetado, acuminado. Tubérculo discal inaparente, região umeral arredondada. Proporção entre o comprimento e a largura do pronoto 1:1,5 (Figuras 1 e 5A). Escutelo triangular, negro, superfície esculturada e brilhante; processo do escutelo de bordos paralelos e ápice arredondado. Proporção entre a largura na base e o comprimento 1:0,92.

Hemiélitros com a membrana, maior parte do clavo e pequena porção do corium castanho-escuras; base do clavo clara; maior parte do corium alaranjada; nervuras da membrana castanho-escuro, tornando-se alaranjadas ao adentrarem no corium. Superfície da asa com grande quantidade de micropelos esparsamente distribuídos.

Conexivos ultrapassando os limites das asas, alaranjados, com as suturas intersegmentais envolvidas por uma faixa negra estreita, praticamente ausente entre o segundo e terceiro segmentos. Bordos laterais do conexivo com micropelos negros, decumbentes (Figuras 1 e 5A). Abdome ventralmente convexo, negro, com a superfície recoberta por micropelos decumbentes, bordos laterais onde se unem aos conexivos castanhoalaranjados com limites sinuosos. Conexivos ventralmente alaranjados (Figuras 1 e 5A).

Pernas com os três pares de cor castanho-escura, coxa, trocânter e fêmur cobertos de micropelos, tíbia e tarso com pelos mais longos. Primeiro e segundo par de fêmures no terço apical da face interna com uma pequena projeção dentiforme.

Genitália do macho: Parâmeros (Pa) cilíndricos com ápice superior dilatado, apresentando uma pequena projeção mais quitinizada, com superfície externa e interna com numerosas cerdas, levemente sinuoso quando visto de perfil (Figuras 7A e 7B). Falo constituído por um aparelho articular (Apb) e um edeago (Ae) de proporções próximas (Figuras 8A, 8B e 8C).

Aparelho articular constituído pela placa basal (Plb) tubuliforme, dobrada, bastante quitinizada, encimada por uma estrutura laminar, retangular, denominada de extensão mediana da placa basal (Eplb); abaixo desta está localizado o processo do gonoporo ( $\mathrm{PrG}$ ): tubuliforme, oco, com a base estreitada presa à ponte basal (PB) e o ápice alongado preso ao edeago. 
A

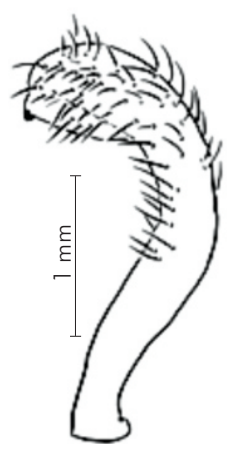

B

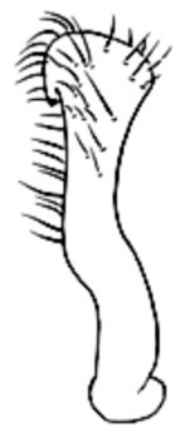

C

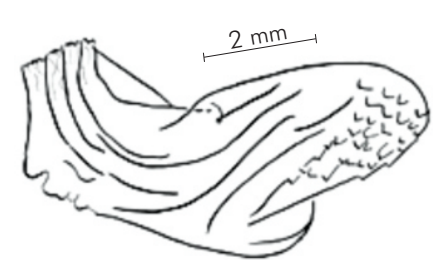

$\mathbf{F}$

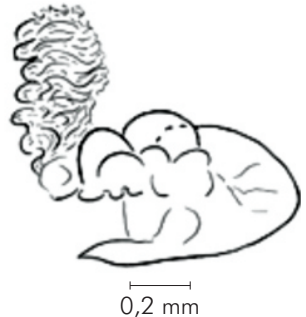

D

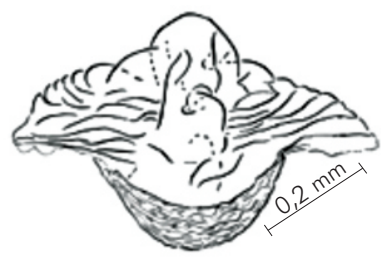

E

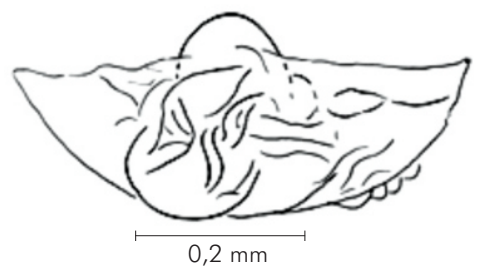

G

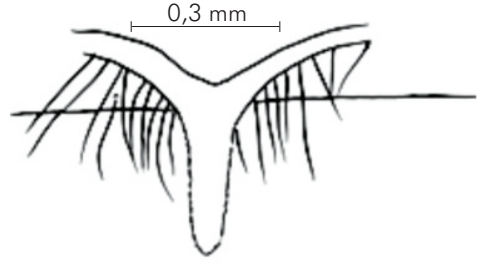

A - Parâmero; vista dorsal; B - Parâmero; vista de perfil; C - Processo do endosoma; D - Vesica, vista dorsal; E - Vesica, vista ventral; F - Vesica, vista de perfil; G - Processo mediano do pigóforo.

Figura 7 - Triatoma pintodiasi sp. nov.

A

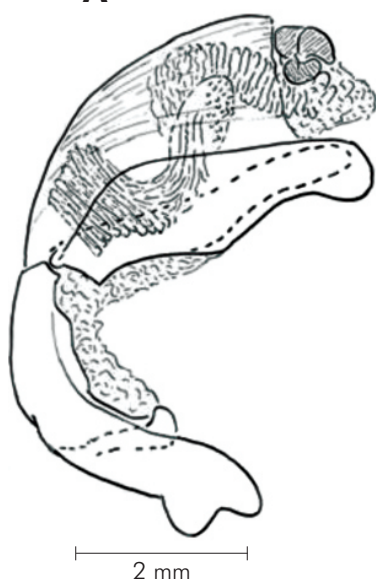

B

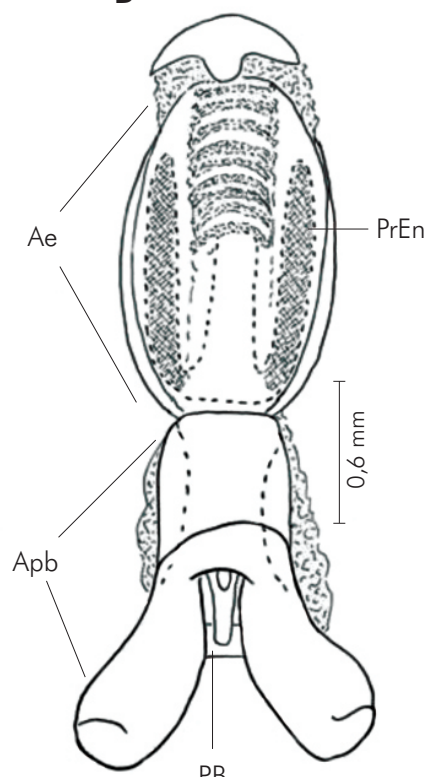

C

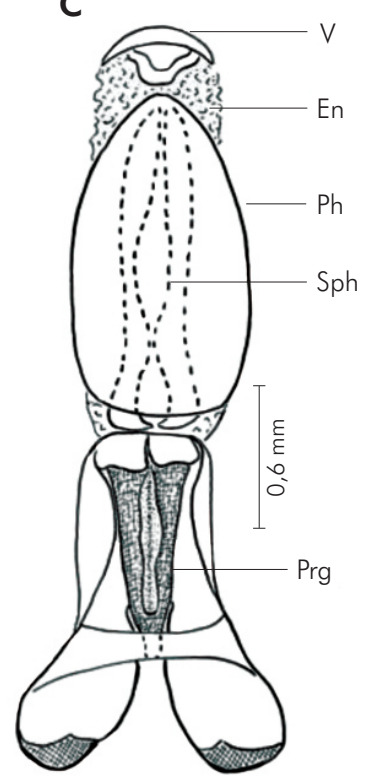

A - Falo; vista lateral; B - Falo; vista dorsal; C - Falo; vista ventral [Ae - Edeago; Apb - Aparelho articular; PrEn - Processo do endosoma; PB - Placa Basal; V - Vesica; En - Endosoma; Ph - Falosoma; $\mathrm{SPh}$ - Suporte do falosoma; Prg - Processo do gonoporo].

Figura 8 - Triatoma pintodiasi sp. nov.

Edeago (Ae) ovoide constituído por um falosoma $(\mathrm{Ph})$ representado por uma placa laminar que serve de assoalho ao conjunto do endosoma, $1+1$ processos do endosoma (PrEn), vesica $(\mathrm{V})$ e conjuntiva $(\mathrm{C} i)$, que recobre o conjunto (Figuras 8A, 8B e 8C; Figuras 7A, 7B, 7C, 7D, $7 \mathrm{E} \mathrm{e} 7 \mathrm{~F})$. Processo do endosoma constituído por uma placa laminar ovoide com numerosos espinhos na parte apical (Figura 7C). Vesica com estrutura triangular, levemente quitinizada (Figuras 7D, 7E e 7F). Processo mediano do pigóforo (PrP) constituído por uma projeção cilíndrica implantada na base inferior e posterior do pigóforo, com bordas ligeiramente onduladas (Figura 7G).

Material-tipo: Holótipo macho $\mathrm{n}^{\circ} 3341$, Brasil, Vila Nova do Sul, RS, 30²0'17,20"S, 5352'32,92"O, IX.2006, Vanda Cunha. Parátipos machos $n^{\circ} 3342$, 3343, 3344, 3345, Brasil, Caçapava do Sul, Serra do Picado, RS, VI.2008, V Cunha e DS Rocha. Parátipo fêmea n 3346, Brasil, Caçapava do Sul, Serra do Picado, RS, VI.2008, V Cunha e DS Rocha (criado no insetário 
do LNIRTT). Parátipos fêmeas $n^{\circ} 3347,3349$, Brasil, Vila Nova do Sul, RS, 30²0'17,20"S, 5352'32,92"O, IX.2006, Vanda Cunha. Parátipo fêmea n ${ }^{\circ} 3348$, Brasil, Vila Nova do Sul, RS, 30²0'17,20"S, 5352'32,92"O, VII.2007, Vanda Cunha. Parátipo macho $n^{\circ} 3350$, Brasil, Caçapava do Sul, Sítio do Picadinho, RS, VI.1997 (determinado como T. circummaculata por $\mathrm{H}$. Lent). Parátipos machos $n^{\circ} 3351,3352,3353$, Brasil, São Jerônimo, Fernão Dias, RS, II.2007, V. Cunha. Parátipo macho no 3354, Brasil, Caçapava do Sul, RS, VI.2008, V. Cunha e DS Rocha (criado no insetário do LNIRTT). Parátipo fêmea n 3355, Brasil, Caçapava do Sul, RS, VI.2008, V. Cunha e DS Rocha (criado no insetário do LNIRTT).

Material de T. circummaculata examinado: Fêmea $\mathrm{n}^{\circ}$ 3338, Uruguai, Sierra Morone, 19.XII.1960, SJ e LC de Zoleosi. Fêmea n⿳ 3339, Uruguai, Sierra de Quebracho, III.1959, CL e CS Carbonell. Macho n 3340, Uruguai, Sierra de Quebracho, III/1959, CL e CS Carbonell. Ninfa de $3^{\circ}$. estádio n ${ }^{\circ}$ 977, Uruguai, IX.1941, R Talice. Ninfa de $5^{\circ}$. estádio nº 979, Uruguai, IX.1941, R Talice. Fêmea $n^{\circ}$ 973, Uruguai, IX.1941, R Talice. Macho ${ }^{\circ}$ 971, Uruguai, IX.1941, R Talice. Machos n 981, 983, 984, Estância Rancho Verde, D. Pedrito, RS, em curral de pedras, XII.1946, J Salles. Fêmea n 3338, Uruguai, Sierra Morone, 19.XII.1960, SJ e LC de Zoleosi. Fêmea $n^{\circ}$ 3339, Uruguai, Sierra del Quebracho, III.1959, CC e CS Carbonell. Macho $n^{\circ} 3340$, Uruguai, Sierra del Quebracho, III.1959, CC e CS Carbonell.
Morfometria geométrica: Os resultados da ACP mostram que os dois primeiros componentes principais juntos representam $73,2 \%$ da variabilidade total (CP $1=51,7 \%$ e CP $2=21,5 \%)$. Projetando os dois componentes principais num eixo de coordenadas (mapa fatorial), onde a distribuição das espécies é representada por polígonos, observa-se que, em função de CP 1, é possível discriminar T. rubrovaria; enquanto pelo CP 2 discriminam-se T. carcavalloi, T. pintodiasi sp. nov. e T. circummaculata (Figura 9). A partir dos componentes canônicos (Canons) pode-se observar uma discriminação mais nítida entre as espécies, tanto pelo Canon 1 como pelo Canon 2 (Figura 10).

Análise da hemolinfa: A eletroforese em gel de poliacrilamida revelou que nas hemolinfas de T. pintodiasi sp. nov. e de T. circummaculata existem proteínas com pesos moleculares variando de 4 a $250 \mathrm{KDa}$. A maioria das proteínas da hemolinfa possui elevado peso molecular e se encontra na região entre 50 e $250 \mathrm{KDa}$. Em ambas hemolinfas não foi observada a presença de proteína em quantidades significativas na faixa de peso da anidrase carbônica (36 KDa) ou da BSA (98 KDa), porém observou-se a presença de proteínas de peso molecular de $60 \mathrm{KDa}$ e $120 \mathrm{KDa}$. Diferenças significativas podem ser observadas entre a hemolinfa de $T$. pintodiasi sp. nov. e T. circummaculata, sendo as proteínas com peso molecular $4 \mathrm{KDa}, 60 \mathrm{KDa}$ e $120 \mathrm{KDa}$ significativamente mais abundantes em termos percentuais na nova espécie (Figuras 11 e 12).
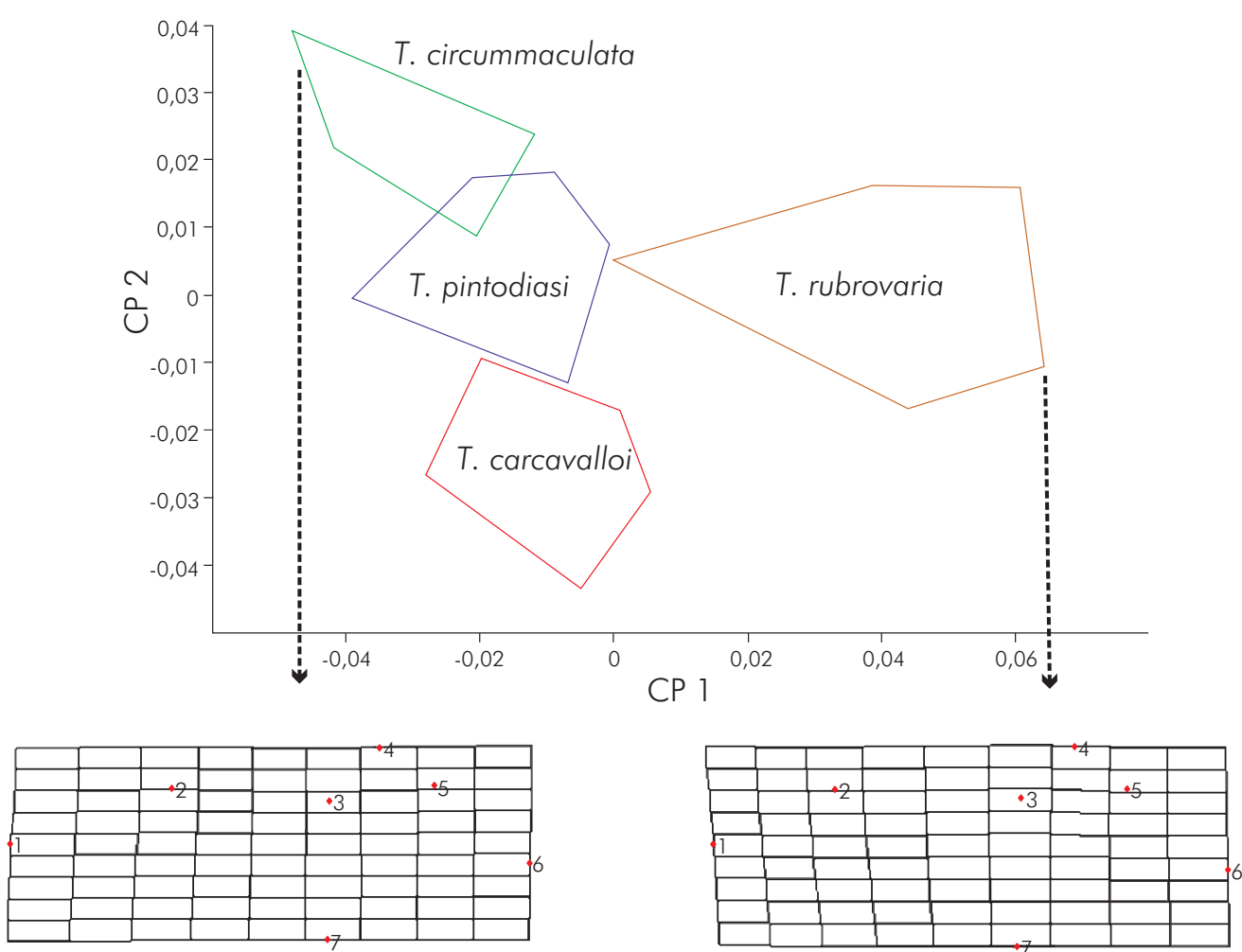

As grades de transformação correspondem à mudança na conformação associada aos valores extremos do eixo do componente principal (CP1), indicado pelas linhas pontilhadas e setas. Através de CP1 pode-se distinguir T. rubrovaria, enquanto pelo CP2 distinguem-se as demais espécies analisadas.

Figura 9 - Análise dos componentes principais (ACP) obtidos a partir da morfometria das cabeças de Triatoma pintodiasi sp. nov., T. rubrovaria (Blanchard, 1843), T. carcavalloi Jurberg, Rocha e Lent, 1998 e T. circummaculata (Stål, 1859) 


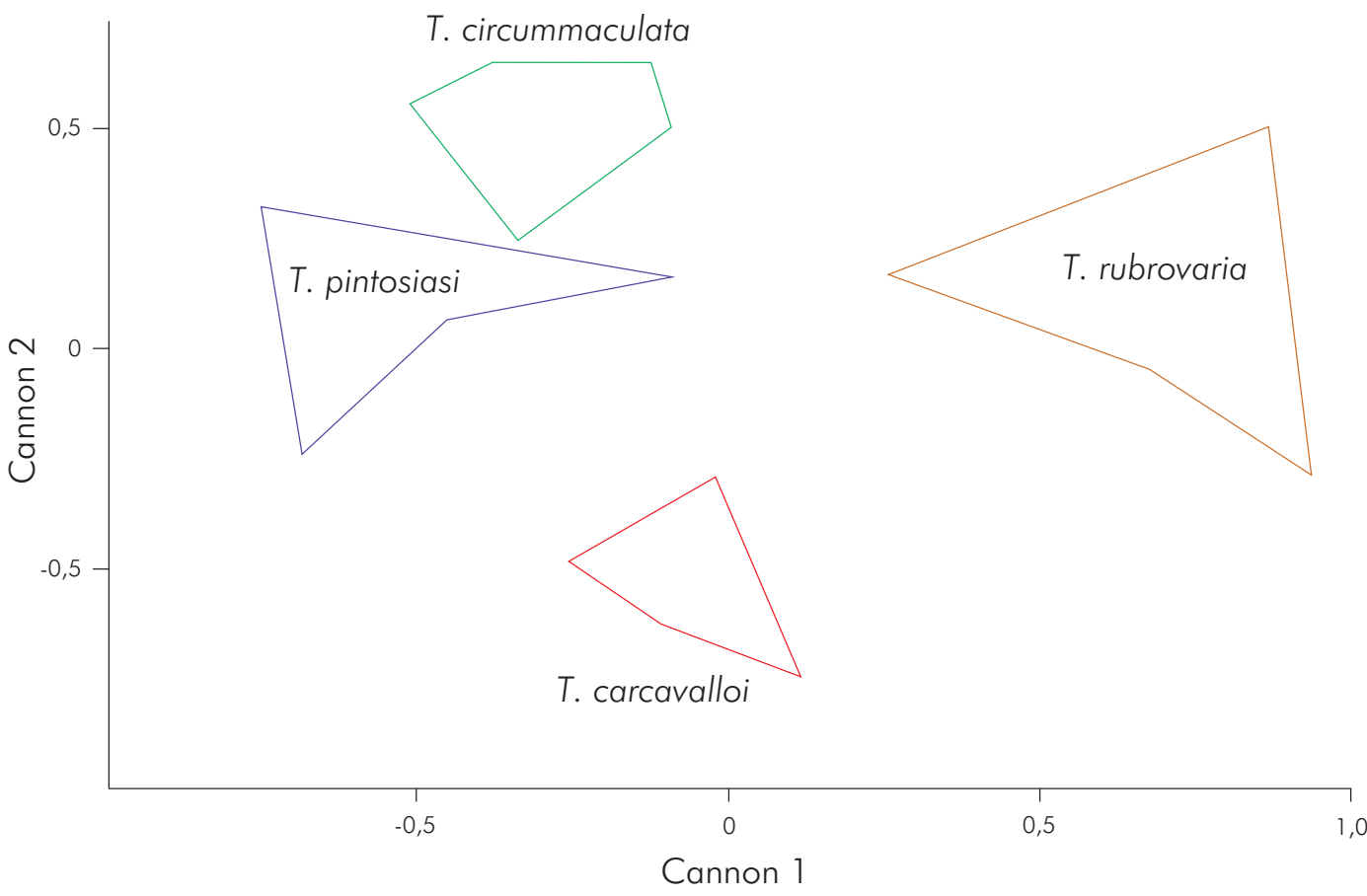

Figura 10 - Mapa fatorial baseado na morfometria geométrica da cabeça de adultos de Triatoma pintodiasi sp. nov., T. rubrovaria (Blanchard, 1843), T. carcavalloi Jurberg, Rocha e Lent, 1998 e T. circummaculata (Stål, 1859), mostrando a discriminação das espécies de acordo com os componentes canônicos

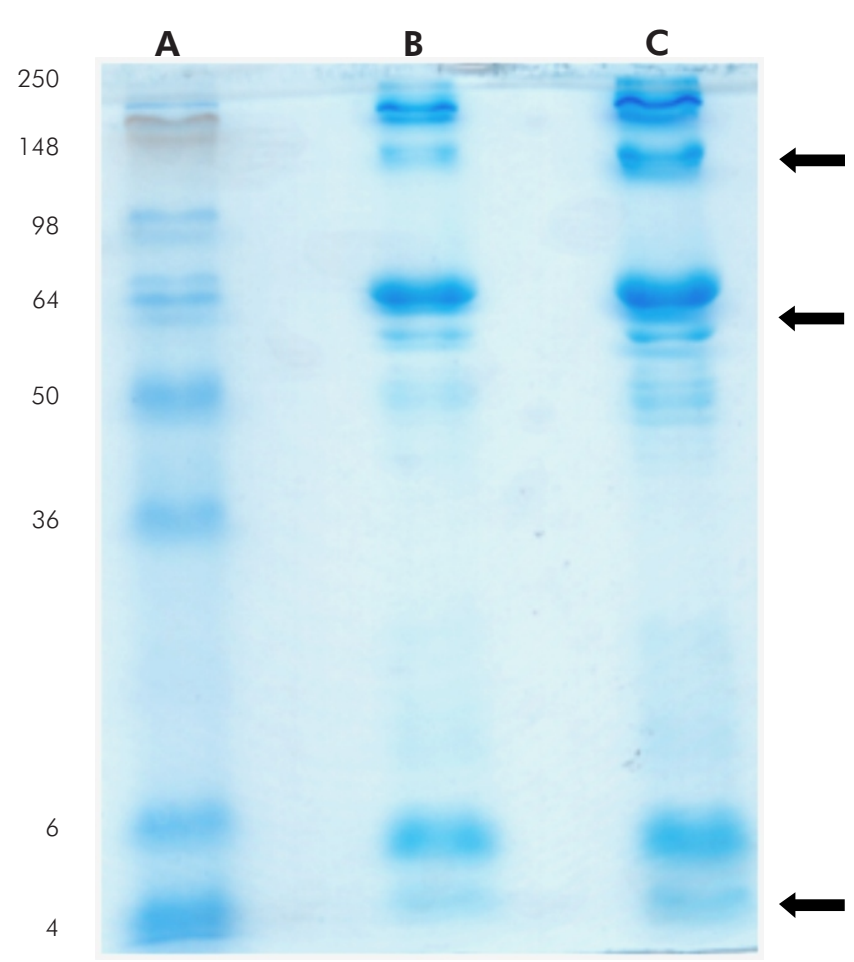

A - Padrões de peso molecular: Miosina (250 KDa), fosforilase (148KDa), BSA (98KDa), dehidrogenase glutâmico (64KDa), álcool dehidrogenase (50KDa), anidrase carbônica (36KDa), aprotinina $(6 \mathrm{KDa})$ e insulina $(4 \mathrm{KDa}) ; \mathrm{B}$ - Hemolinfa de $T$. circummaculata; C - Hemolinfa de T. pintodiasi sp. nov. As setas indicam as proteínas de pesos moleculares para as quais houve diferença significativa entre as duas espécies (4 KDa, 60 KDa e $120 \mathrm{KDa})$.

Figura 11 - Gel de eletroforese (SDS-PAGE) das hemolinfas de T. pintodiasi sp. nov. e T. circummaculata (Stål, 1859)

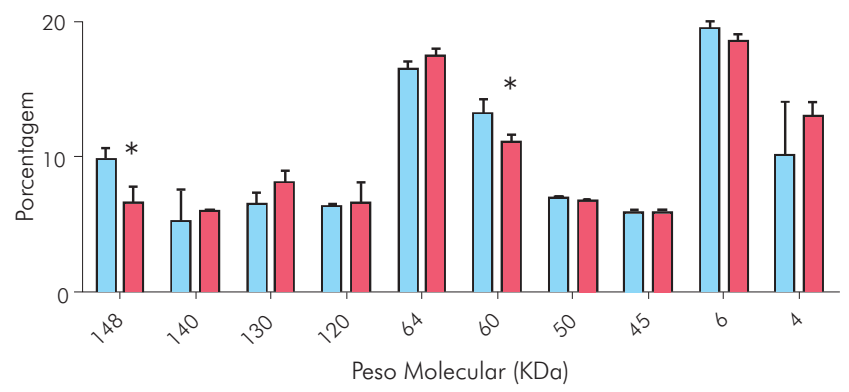

Figura 12 - Densitometria das bandas do gel de eletroforese das hemolinfas de T. circummaculata (Stål, 1859) e T. pintodiasi sp. nov. As duas espécies possuem porcentagem semelhantes para algumas proteínas, como a de peso molecular de 250 $\mathrm{KDa}$, mas a maioria das proteínas possui maior porcentagem em T. pintodiasi sp. nov.

\section{DISCUSSÃO}

Carcavallo et al ${ }^{16}$ publicaram uma monografia acerca da filogenia dos triatomíneos e mantiveram o "complexo Triatoma circummaculata", inicialmente criado por Lent e Wygodzinsky (1979), para a espécie nominativa e T. limai (Del Ponte, 1929). Os adultos de tais espécies, diferentemente de outros Triatoma, apresentam $\circ 2^{\circ}$ e $3^{\circ}$ segmentos do rostro de mesmo comprimento e achatados, o que levou inclusive à sua localização no gênero Neotriatoma Pinto, 1931 durante vários anos. 
Ainda segundo Carcavallo et $a^{16}, T$. rubrovaria faria parte do "complexo Triatoma infestans", juntamente com a espécie que lhe dá o nome e mais T. platensis (Neiva, 1913), T. delpontei (Romaña e Abalos, 1947), T. melanosoma (Martínez, Olmedo e Carcavallo, 1947) e T. carcavalloi. Posteriormente, Schofield e Galvão ${ }^{17}$ sugeriram que o "complexo infestans" teria na verdade seis subcomplexos, incluindo o "subcomplexo rubrovaria", composto por seis espécies: T. carcavalloi, T. circummaculata, T. klugi Carcavallo, Jurberg, Lent e Galvão, 2001, T. limai, T. oliveirai (Neiva, Pinto e Lent, 1939) e T. rubrovaria. Com base na marcante semelhança com $T$. carcavalloi e $T$. circummaculata, T. pintodiasi sp. nov. é assinalada para tal subcomplexo, sendo considerada uma espécie críptica com relação à última.

Para a nominação definitiva da nova espécie, foram analisadas, além do material mencionado nos resultados, as fotos do holótipo e dois parátipos de T. circummaculata depositados no Zoologisches Museum de Berlim (Figura 3). Assim, foi possível observar divergências no padrão cromático entre a nova espécie e T. circummaculata, principalmente no vermelho-alaranjado do lobo posterior do pronoto e do conexivo. Somando-se a isso as diferenças morfocromáticas e das estruturas fálicas (Tabelas 1 e 2; Figura 13), juntamente com os fatores morfométricos e bioquímicos supracitados, é possível estabelecer a nova espécie com alto grau de certeza.

Ao definir-se T. pintodiasi sp. nov., foi utilizada uma ferramenta que tem sido útil desde 1965, quando foi descrito Psammolestes tertius Lent e Jurberg, 1965, seguido de muitas espécies do gênero Triatoma. Ao longo do tempo, já foram publicados dezenove artigos científicos utilizando as estruturas fálicas e proporções da cabeça como uma opção importante na taxonomia do grupo. A associação de parâmetros morfométricos a padrões cromáticos e morfologia de órgãos internos, como glândulas salivares ${ }^{18}$ e túbulos testiculares, corroboraram a definição não só de espécies como também de gêneros (Mepraia ${ }^{19,20,21}$ Mazza, Gajardo e Jörg, 1940, Hermanlentia 19,21 Jurberg e Galvão, 1997, Rhodnius ${ }^{19,21}$ Stål, 1859, Triatoma $22,23,24,25,26,27,28,29$, Panstrogylus ${ }^{19,21}$ Berg, 1879, Psammolestes ${ }^{21,30}$ Bergroth, 1911 , Bolbodera ${ }^{31}$ Valdés Ragués, 1910, Belminus ${ }^{21,31}$ Stål, 1859, Microtriatoma ${ }^{30,31}$ Prosen e Martínez, 1952 e Parabelminus ${ }^{30,31}$ Lent, 1943) em Triatominae. A esta ferramenta, soma-se a utilização de modernas técnicas de análise bioquímica e a morfometria geométrica com uso de análises computacionais, que promovem uma sustentação mais robusta de status específicos ou genéricos.

Tabela 1 - Características morfológicas diferenciais entre T. pintodiasi sp. nov. e T. circummaculata (Stål, 1859)

\begin{tabular}{|c|c|c|c|}
\hline Estrutura & Triatoma pintodiasi & $\begin{array}{l}\text { Triatoma circummaculata } \\
\text { [Lent e Wygodzinsky (1979)] }\end{array}$ & $\begin{array}{c}\text { Triatoma circummaculata } \\
\text { [Coleção Herman Lent - } \\
\mathrm{N}^{\circ} .971 \text { ] }\end{array}$ \\
\hline Comprimento do corpo & 송 $15 \mathrm{~mm}$ 우 $16 \mathrm{~mm}$ & $15-16 \mathrm{~mm}$ & - \\
\hline $\begin{array}{l}\text { Razão comprimento da cabeça: } \\
\text { comprimento do pronoto }\end{array}$ & $1: 0,79$ & - & $1: 0,74$ \\
\hline Largura umeral do pronoto & $3,75 \mathrm{~mm}$ & $3,00 \mathrm{~mm}$ & $3,43 \mathrm{~mm}$ \\
\hline Largura do pronoto no colar & 1,25 & - & $1,06 \mathrm{~mm}$ \\
\hline $\begin{array}{l}\text { Razão comprimento da cabeça: largura ao } \\
\text { nível dos olhos }\end{array}$ & $1: 0,8$ & $1: 0,4-0,5$ & - \\
\hline Razão largura do olho: distância interocular & $1: 1,66$ & $1: 1,35-1,75$ & - \\
\hline Proporção entre artículos do rostro & $1: 2,5: 2,25$ & $1: 2: 2$ & \\
\hline Proporção entre artículos da antena & $1: 4,13: 2,66: 2,33$ & $1: 3,3-4,0: 3,0-4,2: 2,0-2,7$ & - \\
\hline Razão comprimento: largura do escutelo & $1: 1$ & - & $1: 1,28$ \\
\hline Largura do abdome & $6,85 \mathrm{~mm}$ & $5,0-6,0 \mathrm{~mm}$ & - \\
\hline
\end{tabular}

Tabela 2 - Características fálicas diferenciais entre T. pintodiasi sp. nov. e T. circummaculata (Stål, 1859)

\begin{tabular}{lcc}
\hline \multicolumn{1}{c}{ Estrutura } & Triatoma pintodiasi & $\begin{array}{c}\text { Triatoma circummaculata } \\
\text { [Coleção Herman Lent - N. 971] }\end{array}$ \\
\hline Parâmero & Maior (Figuras $8 \mathrm{C} \mathrm{e} \mathrm{7A)}$ & Menor (Figura 14A e 14B) \\
Vesica & Complexa (Figura 7D, 7E e 7F ) & Rudimentar (Figura 15C) \\
Processo do endosoma & Muitos dentes no ápice (Figura 7B) & Poucos dentes no ápice (Figura 15) \\
Suporte do falosoma & Braços separados no ápice (Figura 8B) & Braços unidos no ápice (Figura 16) \\
\hline
\end{tabular}


A

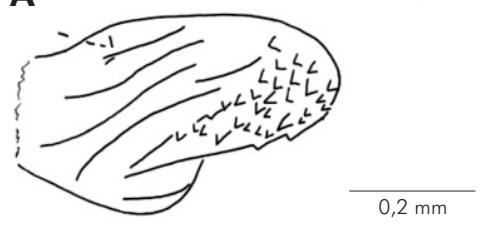

E

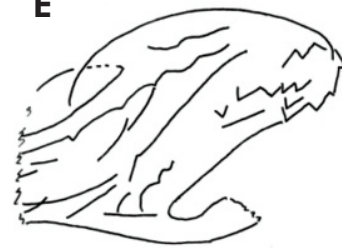

B<smiles>Fc1ccccc1</smiles>

C
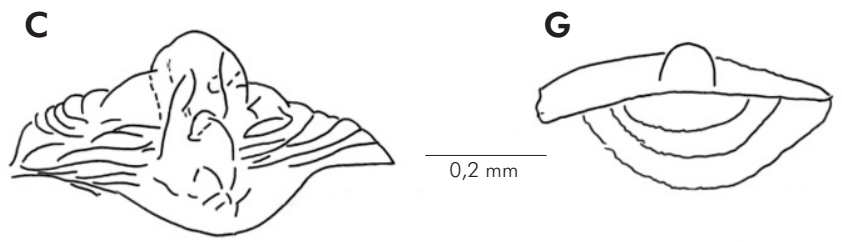

D

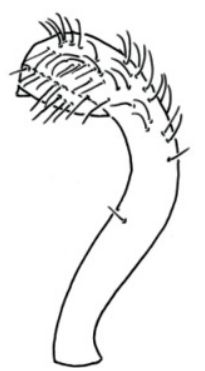

H

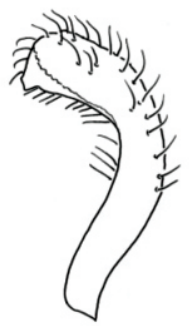

A - Processo do endosoma; T. pintodiasi; B - Suporte do falosoma; T. pintodiasi; C - Vesica; T. pintodiasi; D - Parâmero; T. pintodiasi; E Processo do endosoma; T. circummaculata; $F$ - Suporte do falosoma; T. circummaculata; G - Vesica; T. circummaculata; H - Parâmero; T. circummaculata.

Figura 13 - Visão comparativa das estruturas fálicas de T. pintodiasi sp. nov. e T. circummaculata (Stål, 1859)
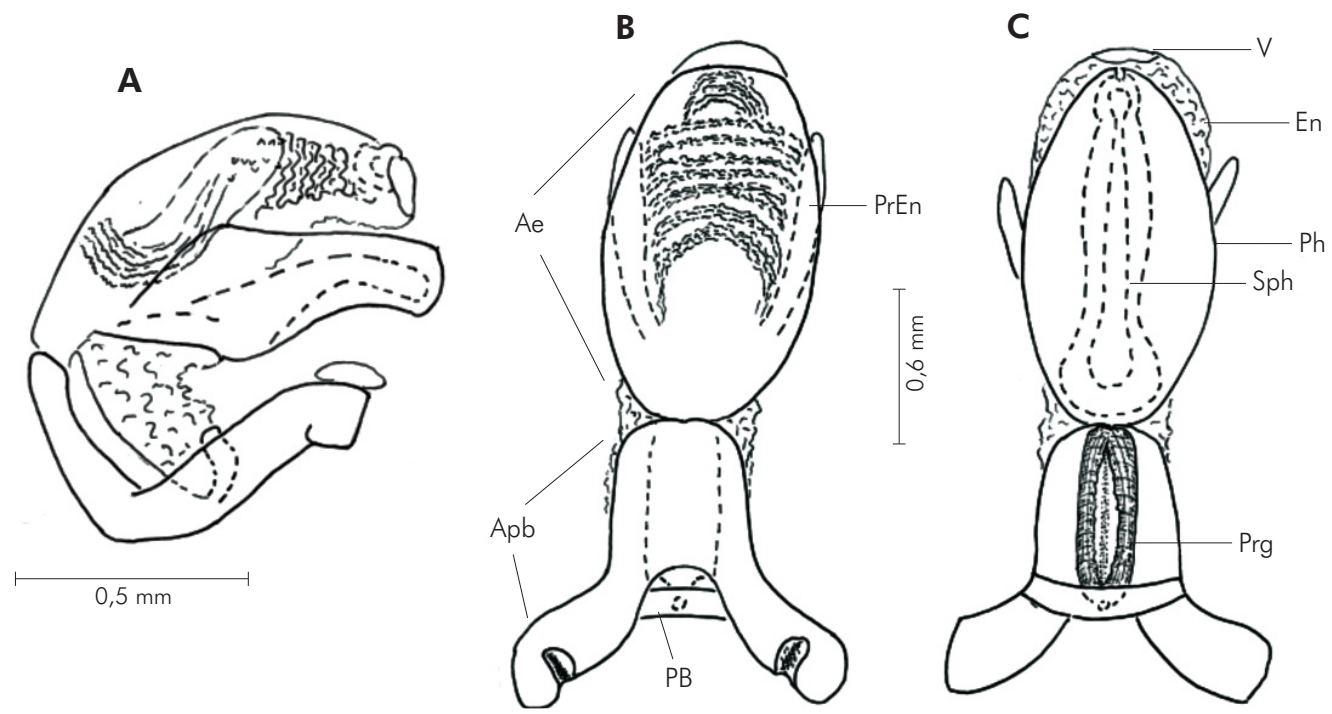

A - Falo visto de perfil; B - Falo em vista dorsal; C - Falo em vista ventral [Coleção Herman Lent - № 971. Ae - Edeago; Apb - Aparelho articular; PrEn - Processo do endosoma; PB - Placa Basal; V - Vesica; En - Endosoma; Ph - Falosoma; SPh - Suporte do falosoma; Prg - Processo do gonoporo].

Figura 14 - Triatoma circummaculata (Stål, 1859) 
A

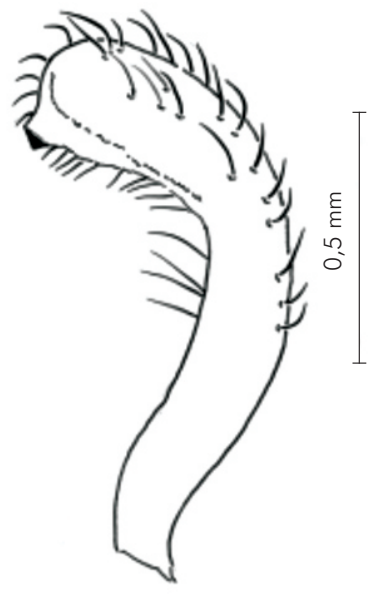

B

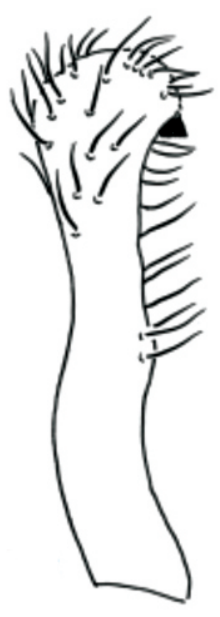

C

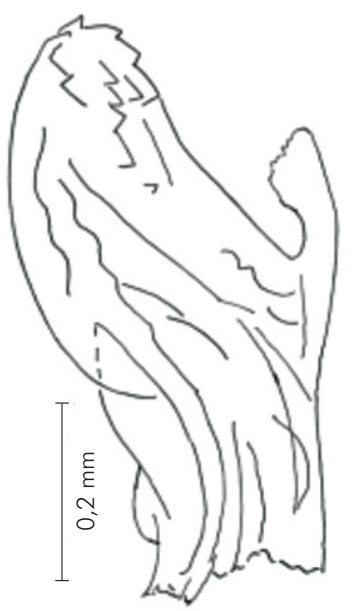

D

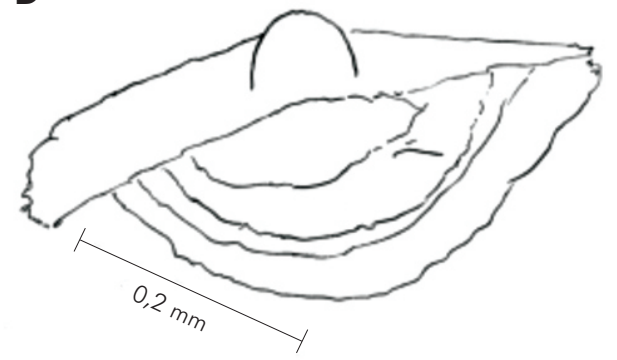

E

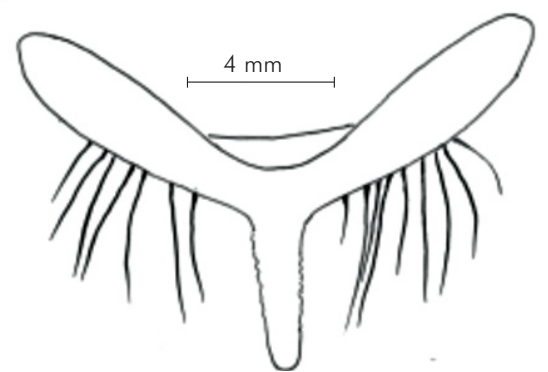

A - Parâmero, vista dorsal; B - Parâmero, vista de perfil; C - Processo do endosoma; D - Vesica; E - Processo mediano do Pigóforo.

Figura 15 - Triatoma circummaculata (Stål, 1859)

A

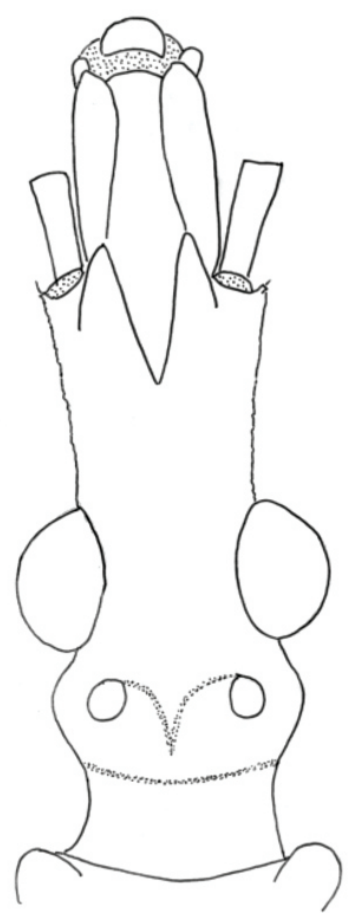

B

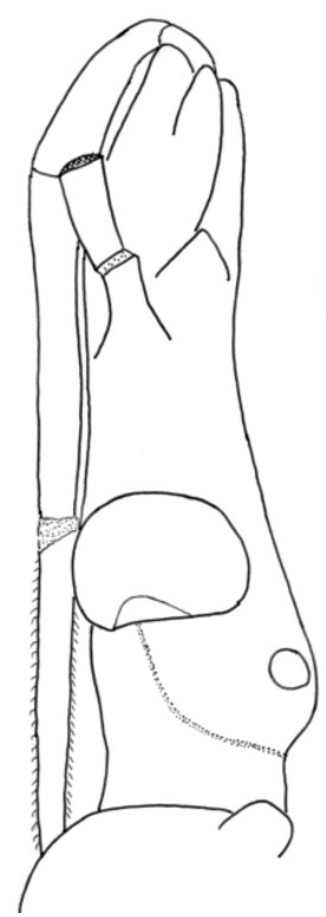

A - Macho; cabeça, vista dorsal; B - Macho; cabeça, vista lateral [Coleção Herman Lent - № 971].

Figura 16 - Triatoma circummaculata (Stål, 1859)

Com relação aos aspectos biológicos das espécies do subcomplexo, Lorosa e colaboradores ${ }^{32}$ concretizaram um experimento em laboratório com T. circummaculata e T. rubrovaria recém-capturados em pedregais, onde conviviam com dictiópteros do gênero Hormetica (Burmeister, 1838). Seu ciclo biológico, do primeiro estádio até adulto, foi completado às expensas da hemolinfa de blatídeos. T. circummaculata completou o ciclo em 322 dias e T. rubrovaria em 284 dias, sendo que os adultos não conseguiram sobreviver alimentando-se somente com hemolinfa. Em experimentos anteriores, Carcavallo e Martínez ${ }^{1}$ conseguiram fechar o ciclo biológico de $T$. rubrovaria em laboratório em 94 dias $^{33}$. Posteriormente, Ruas Neto et al ${ }^{34}$ concretizaram o ciclo de T. circummaculata, T. rubrovaria e T. carcavalloi com três fontes alimentares: aves, répteis e blatídeos. Após a presente publicação, serão feitos estudos em laboratório para avaliar o ciclo de vida e a alimentação de T. pintodiasi sp. nov. e comparálos com os de tais espécies.

Essas espécies são simpátricas e encontradas no sul da região neotropical. Triatoma circummaculata distribuise no Brasil e Uruguai, em latitudes de $28^{\circ}$ a $35^{\circ} \mathrm{Sul}$, de 100 a 500 m de altitude, em floresta tropical, subtropical e savanas. Já T. carcavalloi encontra-se somente no Estado do Rio Grande do Sul, Brasil. Por fim, T. rubrovaria é uma espécie silvestre do Brasil, Uruguai e Argentina, encontrada entre as coordenadas geográficas $25^{\circ}$ e $35^{\circ}$ 
Sul, a até $500 \mathrm{~m}$ de altitude, sendo raramente coletada em habitações humanas, onde não coloniza 7,19,35. A nova espécie, por sua vez, é conhecida até o momento apenas do Rio Grande do Sul, em latitudes próximas a $30^{\circ} \mathrm{Sul}$, onde foi coligida em ambientes pedregosos. Vivendo em locais protegidos, estes triatomíneos sofrem menos com as alterações climáticas acentuadas do sul do continente, visto que temperaturas abaixo de $20^{\circ} \mathrm{C}$ afetam o metabolismo, a demanda de sangue, o tempo de duração do ciclo vital e alteram a sua reprodução 3,35,36.

Estudos de hibridização também poderão ser feitos com T. pintodiasi sp. nov. e espécies próximas já mantidas em colônias do LNIRTT. Espécies do complexo T. infestans podem inclusive intercruzar-se e formar híbridos naturais, como apontado por Carcavallo et $a^{37}$. Segundo eles, T. rubrovaria e $T$. infestans (Klug, 1834) podem gerar híbridos na natureza, o que levou à descrição de Triatoma bruchi Mazza e Jörg, 1944, mais tarde sinonimizada por Lent como T. rubrovaria.

\section{CONCLUSÃO}

Baseado em análises comparativas morfológicas, fálicas, cromáticas, morfométricas, bioquímicas e biológicas, evidenciou-se a existência de uma nova espécie dentro do subcomplexo Triatoma rubrovaria, sensu Schofield e Galvão (2009), o qual, a partir do presente, fica constituído de sete espécies, a saber: T. carcavalloi, T. circummaculata, T. klugi, T. limai, T. oliveirai, T. rubrovaria e T. pintodiasi sp. nov.
As principais diferenças entre T. pintodiasi sp. nov. e as demais estão na coloração do lobo posterior do pronoto; nas estruturas fálicas, incluindo parâmeros, processo do endossoma, suporte do falosoma e vesica; na bioquímica da hemolinfa, que, analisada através da análise de eletroforese, mostrou possuir proteínas com peso molecular de 4 KDa, 60 KDa e 120 KDa significativamente mais abundantes em termos percentuais do que as espécies comparadas; na morfometria geométrica, como se observa na representação gráfica; e pela manutenção do padrão morfocromático, pois as colônias mantidas no LNIRTT há seis anos não apresentam alterações quanto a este aspecto.

\section{AGRADECIMENTOS}

Ao Conselho Nacional de Desenvolvimento Científico e Tecnológico; à Secretaria de Vigilância Saúde; à Coordenação Geral de Laboratórios de Saúde Pública do Ministério da Saúde no convênio com a Fiocruz; ao sr. Vilceu Sccoti, técnico da $4^{a}$ Regional de Saúde, Santa Maria, Rio Grande do Sul, por seu auxílio nas viagens de campo; ao dr. Juergen Deckert, do Museum für Naturkunde, Leibniz-Institut für Evolutions und Biodiversitätsforschung an der Humboldt-Universität Zu Berlin, que nos doou as três fotos do holótipo e de dois parátipos identificados por Stål em 1859 e conservados em ótimas condições; e à aluna Carolina Branco Dale Coutinho, pelo trabalho realizado na edição e tratamento das imagens.

\title{
Triatoma pintodiasi sp. nov. of the T. rubrovaria subcomplex (Hemiptera, Reduviidae, Triatominae)
}

\begin{abstract}
A new cryptic species of Triatoma which belongs to the T. rubrovaria subcomplex is described. The differences between $T$. pintodiasi sp. nov. and T. circummaculata can be verified in their chromatic characters, morphological distinctions in their phallic structures, such as the paramers, the phallosome support, the endosome process, and the vesica, among others. Biochemical analyses in the hemolymph and a comparison of the morphometric data of the head of both species also showed differences between them and other species of the T. rubrovaria subcomplex.
\end{abstract}

Keywords: Chagas Disease; Taxonomy; Triatominae.

\section{Triatoma pintodiasi sp. nov. del subcomplejo T. rubrovaria (Hemiptera, Reduviidae, Triatominae)}

\section{RESUMEN}

Se describe una nueva especia críptica de Triatoma dentro del subcomplejo T. rubrovaria. Las diferencias entre T. pintodiasi sp. nov. y T. circummaculata incluyen, entre otras, el patrón cromático y diferencias morfológicas tanto en las estructuras fálicas, como en los parámetros, soporte del falosoma, proceso del endosoma y vesica. Análisis bioquímicos realizados en la hemolinfa y la comparación morfométrica de la cabeza también registraron diferencias entre las dos especies y otras del subcomplejo T. rubrovaria.

Palabras clave: Enfermedad de Chagas; Taxonomia; Triatominae. 


\section{REFERÊNCIAS}

1 Carcavallo RU, Martinez A. Entomoepidemiologia de La Replubica Argentina. Vol. 1. Buenos Aires: Junta de Investigaciones Cientificas de las Fuerzas Armadas Argentinas; 1968. $140 \mathrm{p}$.

2 Jurberg J, Rocha DS, Lorosa ES, Vinhaes MC, Lent H. Uma nova espécie de Triatoma do Estado do Rio Grande do Sul, Brasil (Hemiptera, Reduviidae, Triatominae). Entomol Vectores. 1998;5:295-310.

3 Moreno AR, Carcavallo RU. Enfoque ecológico para a epidemiologia de doença de Chagas nas Américas. In: Carcavallo RU, Galindez-Girón I, Jurberg J, Lent $\mathrm{H}$, editores. Atlas dos vetores da doença de Chagas nas Américas. Vol. 3. Rio de Janeiro: Fiocruz; 1999. p. 981-1101.

4 Jurberg J, Galvão C, Rocha DS, Dale C, Cunha V. Vetores da doença de Chagas no Brasil: região sul. Rio de Janeiro: RVJ; 2012.

5 Lent $H$, Wygodzinsky P. Revision of Triatominae (Hemiptera, Reduviidae), and their significance as vectors of Chagas disease. Bull Am Mus Nat Hist. 1979; 163(3): 123-520.

6 Carcavallo RU, Galvão C, Lent H. Triatoma jurbergi sp. n. do norte do estado de Mato Grosso. Brasil (Hemiptera, Reduviidae, Triatominae) com uma atualização das sinonímias e outros táxons. Mem Inst Oswaldo Cruz. 1998 jul-ago;93(4):459-64.

7 Carcavallo RU, Curto de Casas SI, Sherlock IA, Galindez-Girón I, Jurberg J, Galvão C, et al. Distribuição geográfica e dispersão alti-latitudinal dos triatomíneos. In: Carcavallo RU, Galindez-Girón I, Jurberg J, Lent $H$, editores. Atlas dos vetores da doença de Chagas nas Américas. Vol. 3. Rio de Janeiro: Fiocruz; 1999. p. 747-92.

8 Chagas C. Nova tripanozomiaze humana: estudos sobre morfolojia e o ciclo evolutivo do Schizotrypanum cruzi n. gen. n. sp., ajente etiolojico de nova entidade morbida do homem. Mem Inst Oswaldo Cruz. 1909 ago;1 (2):159-218.

9 Jurberg J, Galvão C, Noireau F, Carcavallo R, Rocha DS, Lent $H$. Uma iconografia dos triatomíneos: (Hemiptera: Reduviidae). Rio de Janeiro: Gama Filho; 2005. 51 p. Co-publicado por Institut de Recherche pour le Développement.

10 RohlfFJ. NTSYS. Numerical taxonomy and multivariate analysis system. Version 2.10p. Setauket: Exeter Software; 2001.

11 Rohlf FJ. TpsRelw for Windows v. 1.17. Thin Plate Spline Relative Warps Analysis. Stony Brook: State University of New York; 1998.

12 SAS Institute. JMP statistics and graphics guide, version 4.0.4. Cary: SAS Institute; 2000.

13 van Sande M, Karcher D. Species differentiation of insects by hemolymph electrophoresis. Science. 1960 Apr;131(3407): 1103-4.
14 Lowry $\mathrm{OH}$, Rosebrough NJ, Farr AR, Randall RJ. Protein measurements with the Folin phenol reagent. J Biol Chem. 1951 Nov;193(1):265-75.

15 Laemmli UK. Cleavage of structural proteins during assembly of the head of bacteriophage T4. Nature. 1970 Aug;227(5259):680-5.

16 Carcavallo RU, Jurberg J, Lent H, Noireau F, Galvão C. Phylogeny of the Triatominae (Hemiptera: Reduviidae): proposal for taxonomic arrangements. Entomol Vectores. 2000;7:1-99.

17 Schofield CJ, Galvão C. Classification, evolution and species groups within the Triatominae. Acta Trop. 2009 May-Jun; 1 10(2-3):88-100.

18 Santos MC, Jurberg J, Galvão C, Lent H. Análise morfológica comparativa do complexo salivar dos Triatominae. Entomol Vectores. 1997;4:155-62.

19 Jurberg J, Galvão C. Biology, ecology and systematics of Triatominae (Heteroptera, Reduviidae) vectors of Chagas disease and implications for human health. Denisia. 2006;19:1096-116.

20 Lent H, Jurberg J, Galvão C. Revalidação do gênero Mepraia Mazza, Gajardo e Jörg, 1940 (Hemiptera, Reduviidae, Triatominae). Mem Inst Oswaldo Cruz. 1994 jul-set;89(3):347-52.

21 Galvão C, Carcavallo RU, Rocha DS, Jurberg J. A checklist of the current valid species of the subfamily Triatominae Jeannel, 1919 (Hemiptera, Reduviidae) and their geographical distribution, with nomenclatural and taxonomic notes. Zootaxa. 2003 May;202: 1-36.

22 Lent $H$, Jurberg J. Algumas informações sôbre Triatoma spinolai Porter, 1934 com um estudo sôbre as genitálias externas (Hemiptera, Reduviidae). Rev Bras Biol. 1967;27:273-88.

23 Lent $H$, Jurberg J. Estudo comparativo da genitália externa masculina de seis espécies de Triatoma Laporte, 1832 que mais frequentemente habitam o domicílio humano no Brasil (Hemiptera, Reduviidae). Rev Bras Biol. 1978;38(4):931-44.

24 Lent $H$, Jurberg J. Sobre a variação intra-específica em T. dimidiata (Latreille) e T. infestans (Klug) (Hemiptera, Reduviidae). Mem Inst Oswaldo Cruz. 1985;80:285-99.

25 Lent $\mathrm{H}$, Jurberg J. Estudo comparativo da genitália externa masculina de Triatoma neotomae Neiva, 1911 e Triatoma nitida Usinger, 1939 (Hemiptera, Reduviidae). Mem Inst Oswaldo Cruz. 1992;87Supl $1: 123-30$.

26 Pires HHR, Barbosa SH, Jurberg J, Diotaiuti L. Comparative studies of distinct populations of Triatoma infestans. V. Morphological patterns of the male genitalia. Mem Inst Oswaldo Cruz. 1995;90 Supl 1:227. 
27 Carcavallo RU, Jurberg J, Lent H, Galvão C, Steindel M, Pinto CJC. Nova espécie do complexo oliveirai (nova denominação para o complexo matogrossensis) (Hemiptera, Reduviidae, Triatominae) do Estado do Rio do Grande do Sul, Brasil. Mem Inst Oswaldo Cruz. $2001 ; 96(1): 71-9$.

28 Carcavallo RU, Jurberg J, Rocha DS, Galvão C, Noireau F, Lent H. Triatoma vandae sp. do complexo oliveirai encontrada no Estado do Mato Grosso, Brasil (Hemiptera: Reduviidae: Triatominae). Mem Inst Oswaldo Cruz. 2002 jul;97:649-54.

29 Papa AR, Jurberg J, Carcavallo RU, Cerqueira RL, Barata JMB. Triatoma sherlocki sp. n. coletada na Bahia, Brasil (Hemiptera, Reduviidae, Triatominae). Entomol Vectores. 2002 fev;9(1):133-46.

30 Lent $H$, Jurberg J. $\bigcirc$ gênero Psammolestes Bergroth, 1911, com um estudo sobre a genitália das espécies (Hemiptera, Reduviidae, Triatominae). Rev Bras Biol. $1965 ; 25(4): 349-76$.

31 Lent $H$, Jurberg J. A genitália externa na Tribo Bolboderini (Hemiptera, Reduviidae, Triatominae). Mem Inst Oswaldo Cruz. 1984 jan-mar;79(1):1-27.

32 Lorosa ES, Jurberg J, Souza ALA, Vinhaes MC, Nunes IM. Hemolinfa de Dictyoptera na manutenção do ciclo biológico silvestre de Triatoma rubrovaria Blanchard, 1843 e Triatoma circummaculata (Stal,
1859) (Hemiptera, Reduviidae, Triatominae). Entomol Vectores. 2000;7(3):287-96.

33 Canale DM, Jurberg J, Carcavallo RU, Galvão C, Galindez-Girón I, Mena Segura CA, et al. A bionomia de algumas espécies. In: Carcavallo RU, GalindezGirón I, Jurberg J, Lent H, editores. Atlas dos Vetores da Doença de Chagas nas Américas. Vol. 3. Rio de Janeiro: Fiocruz; 1999. p. 839-90.

34 Ruas Neto AL, Corseuil E, Cavalleui A. Development of rupestrian Triatomines (Hemiptera, Reduviidae, Triatominae) following hemolynphagy on Blaberids (Blatodea, Blaberidae) in Rio Grande do Sul State, Brazil. Entomol Vectores. 2007;8:205-16.

35 Curto de Casas SI, Carcavallo RU, Galindez-Girón I, Burgos JJ. Fatores bioclimáticos e zonas de vida. In: Carcavallo RU, Galindez-Girón I, Jurberg J, Lent H, editores. Atlas dos vetores da doença de Chagas nas Américas. Vol. 3. Rio de Janeiro: Fiocruz; 1999. p. 793-838.

36 Clark N. The effect of temperature and humidity upon eggs of the bug, Rhodnius prolixus (Heteroptera, Reduviidae). J Anim Ecol. 1935 May;4(1):82-7.

37 Carcavallo RU, Cichero JA, Martinez A, Prozen AF, Ronderos R. Una nueva espécie de Triatoma Laporte (Hemiptera, Reduviidae, Triatominae). Segundas Jornadas Entomo-epidemiologicas Argentinas. 1967;2:43-8. 